\title{
BNREL
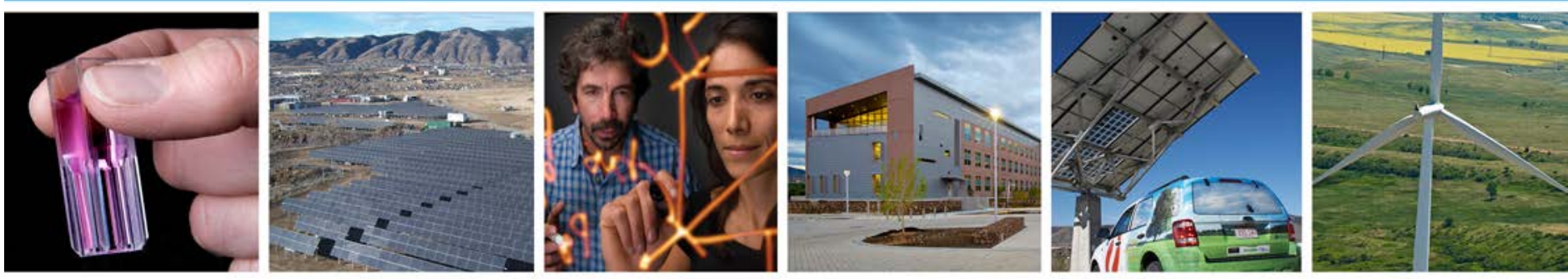

\section{Assessing Fatigue and Ultimate Load Uncertainty in Floating Offshore Wind Turbines Due to Varying Simulation Length}

G. Stewart and M. Lackner

University of Massachusetts

L. Haid and D. Matha

University of Stuttgart

J. Jonkman and A. Robertson

National Renewable Energy Laboratory

Presented at the $11^{\text {th }}$ International Conference on Structural Safety and Reliability

Columbia University, New York, New York

June 16-20, 2013

NREL is a national laboratory of the U.S. Department of Energy

Office of Energy Efficiency \& Renewable Energy

Operated by the Alliance for Sustainable Energy, LLC

This report is available at no cost from the National Renewable Energy

Laboratory (NREL) at www.nrel.gov/publications.

\section{Conference Paper}

NREL/CP-5000-58518

July 2013

Contract No. DE-AC36-08GO28308 


\section{NOTICE}

The submitted manuscript has been offered by an employee of the Alliance for Sustainable Energy, LLC (Alliance), a contractor of the US Government under Contract No. DE-AC36-08GO28308. Accordingly, the US Government and Alliance retain a nonexclusive royalty-free license to publish or reproduce the published form of this contribution, or allow others to do so, for US Government purposes.

This report was prepared as an account of work sponsored by an agency of the United States government. Neither the United States government nor any agency thereof, nor any of their employees, makes any warranty, express or implied, or assumes any legal liability or responsibility for the accuracy, completeness, or usefulness of any information, apparatus, product, or process disclosed, or represents that its use would not infringe privately owned rights. Reference herein to any specific commercial product, process, or service by trade name, trademark, manufacturer, or otherwise does not necessarily constitute or imply its endorsement, recommendation, or favoring by the United States government or any agency thereof. The views and opinions of authors expressed herein do not necessarily state or reflect those of the United States government or any agency thereof.

This report is available at no cost from the National Renewable Energy Laboratory (NREL) at www.nrel.gov/publications.

Available electronically at http://www.osti.gov/bridge

Available for a processing fee to U.S. Department of Energy and its contractors, in paper, from:

U.S. Department of Energy

Office of Scientific and Technical Information

P.O. Box 62

Oak Ridge, TN 37831-0062

phone: 865.576.8401

fax: 865.576 .5728

email: mailto:reports@adonis.osti.gov

Available for sale to the public, in paper, from:

U.S. Department of Commerce

National Technical Information Service

5285 Port Royal Road

Springfield, VA 22161

phone: 800.553 .6847

fax: 703.605.6900

email: orders@ntis.fedworld.gov

online ordering: http://www.ntis.gov/help/ordermethods.aspx 


\title{
Assessing Fatigue and Ultimate Load Uncertainty in Floating Offshore Wind Turbines Due to Varying Simulation Length
}

\author{
G. Stewart \& M. Lackner \\ University of Massachusetts, Amherst, Massachusetts
}

L. Haid \& D. Matha

University of Stuttgart, Stuttgart, Germany

J. Jonkman \& A. Robertson
National Renewable Energy Laboratory, Golden, Colorado

ABSTRACT: With the push towards siting wind turbines in deeper water, floating offshore wind turbines are becoming an economically attractive option. The International Electrotechnical Commission's (IEC) 61400-3 design standard covers fixed-bottom offshore wind turbines, but there are a number of new research questions that need to be answered to modify these standards so that they are applicable to floating wind turbines. One issue is the appropriate simulation length needed for floating turbines. This paper will discuss the results from a study assessing the impact of simulation length on the ultimate and fatigue loads of the structure, and will address uncertainties associated with changing the simulation length for the analyzed floating platform. Recommendations of required simulation length based on load uncertainty will be made and compared to current simulation-length requirements.

\section{INTRODUCTION}

\subsection{Floating Platforms}

Currently installed and operating offshore wind turbines are composed largely of fixed-bottom foundations, which are viable for water depths of up to 60 $\mathrm{m}$. Because much of the offshore wind resource in the United States is located in deeper water, floating platforms have become an economically attractive option, and the subject of much wind-related research. Further development of floating wind turbine technology requires more research, because there are little experimental or prototype data available.

The research presented in this paper makes recommendations on the simulation length necessary to accurately predict loads for a spar-type platform. The wind turbine model used in this study was the National Renewable Energy Laboratory (NREL) offshore 5-MW reference wind turbine (Jonkman et al. 2009). Equipped with variable-speed and collective-pitch control, the machine is rated at 5 MW at a wind speed of $11.4 \mathrm{~m} / \mathrm{s}$. The turbine has a hub height of $90 \mathrm{~m}$ and a rotor diameter of $126 \mathrm{~m}$. The floating platform used for this study was the OC3-Hywind spar buoy, which is a virtual design based on the Statoil spar buoy, but modified to support the NREL 5-MW reference turbine (Jonkman, J. 2009 \& 2010, Jonkman \& Matha 2011).

\subsection{Design Standards}

The IEC 61400-3 fixed-bottom offshore wind turbine design standard recommends 10-minute simulations for design load cases involving normal operation, with at least 6 random wind and wave seeds, resulting in 60 minutes of stochastic wind and wave inputs for each environmental condition (IEC 2005 $\&$ 2009). The 10-minute simulation length is based on the spectral gap of wind variation, which occurs between the turbulent and diurnal peaks in the wind spectrum. Ten minutes of turbulent wind can be approximated as stationary within this frequency band. Experience from the offshore oil and gas industry has led to recommendations of as long as 6 hours for a single floating platform simulation to account for the spectral gap of waves at a lower frequency, low natural frequencies of floating platforms, and second-order slow-drift hydrodynamic effects.

The goal of this simulation-length study was to address these vastly different length recommendations by running simulations of floating wind turbines for varying lengths from 10 minutes to 6 hours, and comparing both ultimate and fatigue loads.

\subsection{Simulation Tools}

The simulation-length study was performed using FAST, a computer-aided engineering (CAE) tool developed by NREL with the support of the U.S. Department of Energy (Jonkman \& Buhl 2005). This 
tool combines a blade-element/momentum aerodynamic solver with a combined multi-body and modal representation structural solver and a first-order radiation and diffraction hydrodynamics module, which also includes Morison's equation. Secondorder hydrodynamics have been shown to be small for the OC3-Hywind floating wind system during normal operation (Roald 2013).

TurbSim was used to create the turbulent wind files (Jonkman, B. 2009). This program uses a spectral representation of the turbulence to create realistic wind fields over the whole rotor of a wind turbine with spatial coherence. MLife, another NREL CAE program, was used to calculate fatigue loads using a rainflow counting algorithm and the probability density function of the wind speed to determine lifetime fatigue damage and damage-equivalent loads (Hayman 2012).

\section{BACKGROUND}

\subsection{Metocean Conditions}

A database of realistic metocean input conditions was created for use in this study and future studies concerning the design standards for floating offshore wind turbines (FOWTs). Data from the National Oceanic and Atmospheric Administration (NOAA) floating data buoys were used to create the database. Because upcoming studies with this metocean dataset will investigate the effect of wind and wave misalignment, buoy data with wind and wave directionality were needed, which limited the number of available buoys. Data from buoys on the East and West coasts of the United States, and the Gulf of Mexico were downloaded from the NOAA website (http://www.ndbc.noaa.gov/), and were postprocessed to remove measurement errors in the data. Figure 1 shows the geographical distribution, mean wind speeds, and mean significant wave heights of the sites.

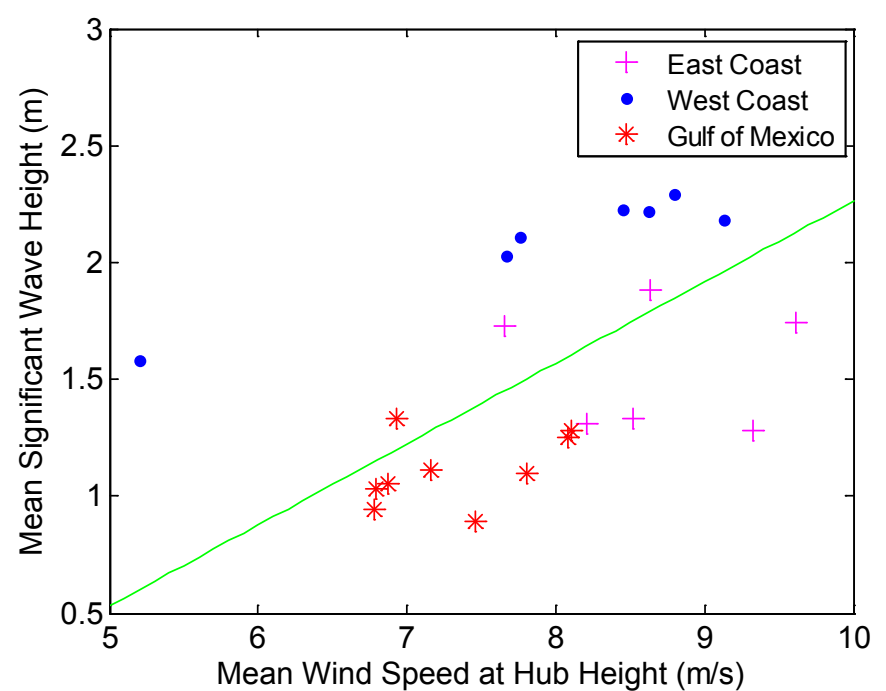

Figure 1. Geographical distribution of mean wind speeds and wave heights.

Using the data from these sites, conditional probability functions were created for four variables: wind speed at hub height, significant wave height, wave peak-spectral period, and wind/wave misalignment angle. Wind speed was treated as independent, and an unconditioned two-parameter Weibull distribution was used to represent the wind speed probability density function (PDF) at each site. Wind/wave misalignment angle was conditioned on wind speed alone, significant wave height is conditioned on wind speed and misalignment angle, and peak-spectral period was conditioned on wind speed and significant wave height. The peakspectral period and significant wave height PDFs were modeled by two-parameter gamma distributions. A Von-Mises distribution (also known as a circular normal distribution) was used for the wind/wave misalignment PDF at each site. These analytical distributions were chosen based on their ability to fit the empirical measured data.

The sites were divided into groups based on geographical region, and the conditional probability distributions from each site within the regions were averaged to create three representative sites (East, West, and Gulf of Mexico). The results presented in this paper used data from the averaged East Coast site, and the simulations used the expected value of significant wave height and median peak-spectral period for each mean wind speed for zero degree wind/wave misalignment, as shown in Table 1. 
Table 1. Expected values of significant wave height and peak-spectral period as a function of hub-height wind speed for the generic East Coast site.

\begin{tabular}{lll}
\hline $\begin{array}{l}\text { Wind speed } \\
(\mathrm{m} / \mathrm{s})\end{array}$ & $\begin{array}{l}\text { Significant wave height } \\
(\mathrm{m})\end{array}$ & $\begin{array}{l}\text { Peak-spectral period } \\
(\mathrm{s})\end{array}$ \\
\hline 4 & 1.10 & 8.52 \\
6 & 1.18 & 8.31 \\
8 & 1.32 & 8.01 \\
10 & 1.54 & 7.65 \\
12 & 1.84 & 7.44 \\
14 & 2.19 & 7.46 \\
16 & 2.60 & 7.64 \\
18 & 3.06 & 8.05 \\
20 & 3.62 & 8.52 \\
22 & 4.03 & 8.99 \\
24 & 4.52 & 9.45 \\
\hline
\end{tabular}

\subsection{Onshore Simulation-Length Study}

During the analysis of the ultimate loads for the floating platform simulations, there was concern that changes in the discretization of the wind turbulence spectrum that TurbSim uses were creating higher maximum wind speeds, and thus higher maximum loads, for longer simulations. This concern prompted an investigation that used a land-based turbine model to isolate loading influences from the wind inputs only.

TurbSim uses a spectral sampling method to create a wind time series from a target wind turbulence spectrum. In this method, the spectrum is discretized and sine waves at each discrete frequency are created with amplitudes corresponding to the power in the spectrum at that frequency and randomized phases. The number of sine waves that make up the time series corresponds to the level of frequency discretization, which increases for longer simulations.

Simulations using a land-based wind turbine were run for varying simulation lengths to assess the effect of discretization on the maximum loads and wind speeds. The land-based study included $10 \times 1$ hour simulations, $12 \times 50$-minute simulations, $15 \times$ 40-minute simulations, $20 \times 30$-minute simulations, $30 \times 20$-minute simulations, and $60 \times 10$-minute simulations, for a total simulation time of 10 hours in each group. We determined that the discrepancies that prompted the study were a result of the comparison of maximum loads from simulations of different length rather than any actual differences in the spectral sampling method. If maximum values that are averaged across simulations of a given length are compared to maximum values averaged across simulations from a different length, the longer simulation length will show higher maximums (see Fig. 2). This indicates that average maximums from a long simulation cannot be compared to the average maximum from a short simulation. Instead, either a single maximum value from 6 10-minute simulations should be compared to the maximum value from 11 -hour sim- ulation (Fig. 3), for example, or the average maximum value of the 610 -minute simulations should be compared to the average maximum value from dividing the 1-hour section into 10 -minute sections (Fig. 4).

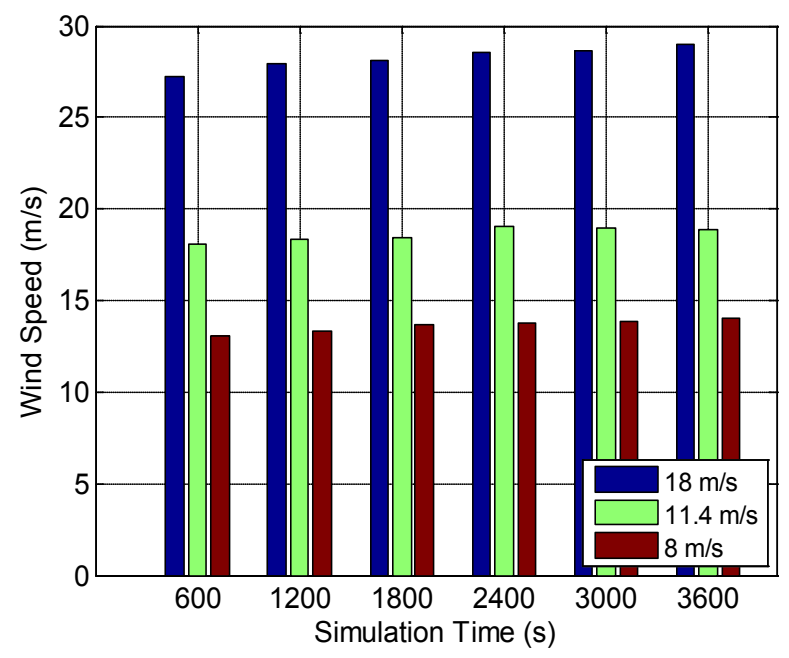

Figure 2. Mean of the maximum wind speeds from each simulation.

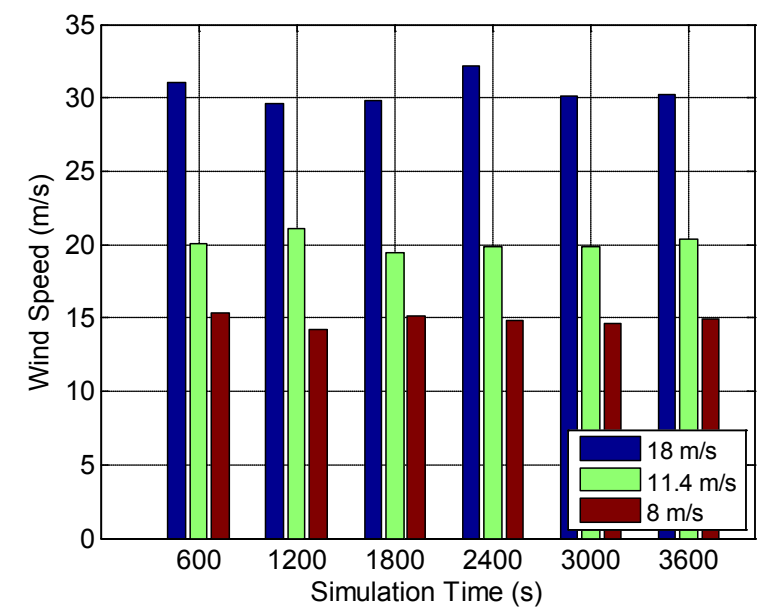

Figure 3. Absolute maximum of wind speeds from all simulations.

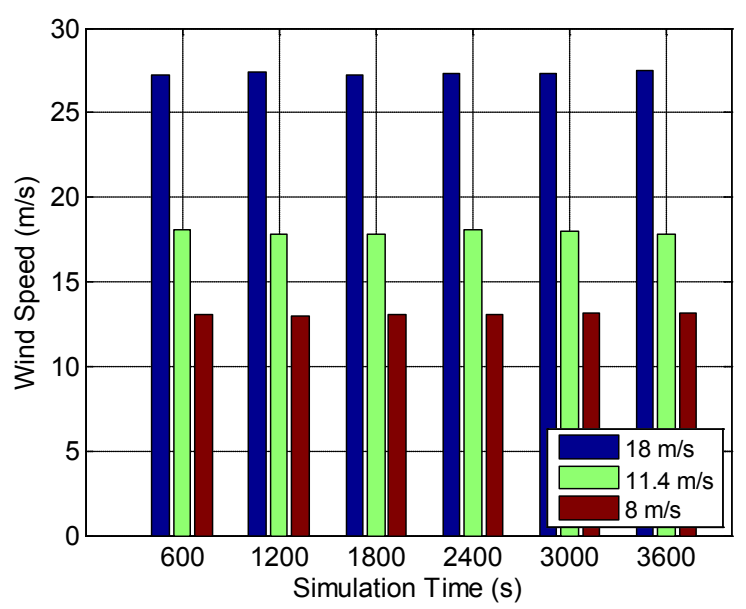

Figure 4. Mean of 10-minute maximums.

The turbine response and loads caused by the aerodynamic loading followed the same trends as the wind statistics shown in Figures 2-4, and so these results are omitted. While these result seem intuitive, it is important to consider the averaging 
techniques used when analyzing simulations of different lengths, and to ensure that only simulations of equal time length are compared.

\subsection{Simulation Details}

Once it was clear that the length of the simulations with only wind inputs had no effect on loads (assuming the same total time across simulation groups), a larger study investigating the effects of both wind and wave inputs was conducted. Using FAST, a series of simulations were run for 11 different wind speeds, using simulation lengths of 10 minutes, 20 minutes, 1 hour, 3 hours, and 6 hours (Haid 2013a). The same total simulation length (60 hours per wind speed bin) was maintained for each simulation group. The expected value of significant wave height and wave peak-spectral period was used for each wind speed bin.

For simulations longer than 10 minutes, repeated periodic wind inputs were used. Time series created from spectral representation methods like the one used in TurbSim are naturally periodic, with the period being the lowest frequency used from the spectrum. For the longer simulations, it was found that the memory requirements for a full turbulent wind file with adequate resolution far exceeded the amount of RAM in most computers. In addition, wind does not stay stationary for much longer than 10 minutes, so simulating longer wind time series from spectral methods, which create stationary data, is not realistic. For these reasons, periodic wind files were used.

Ten unique 10-minute wind files were created for each wind speed bin. These ten files were used for each simulation-length group, and repeated for simulations longer than 10 minutes. In this way, the total length of random wind (100 minutes) is preserved for each simulation length.

Similar efforts were made to keep the total random length of wave inputs equal for different length simulations. Because there are no memory limitations associated with simulating waves, periodic waves are not necessary. This means that a 6-hour simulation will have a full 6 hours of stochastic waves, but only 10 minutes of stochastic (but repeated) wind. To have an equivalent group of 10minute simulations, 36 10-minute simulations were run for each 6-hour simulation. All 36 of these 10minute simulations used the same wind input, to represent the periodic wind input of the longer simulations. Table 2 shows the numbers of simulations for each simulation-length group.
Table 2. Number of simulations for each simulation length

\begin{tabular}{|c|c|c|c|}
\hline $\begin{array}{l}\begin{array}{l}\text { Simulation } \\
\text { length }\end{array} \\
(\mathrm{min})\end{array}$ & $\begin{array}{l}\text { Total number } \\
\text { of simulations } \\
(-)\end{array}$ & $\begin{array}{l}\text { Number of } \\
\text { simulations } \\
\text { per wind bin } \\
(-)\end{array}$ & $\begin{array}{l}\text { Number of } \\
\text { wave seeds } \\
\text { per wind seed } \\
(-)\end{array}$ \\
\hline 10 & 3960 & 360 & 36 \\
\hline 20 & 1980 & 180 & 18 \\
\hline 60 & 660 & 60 & 6 \\
\hline 180 & 220 & 20 & 2 \\
\hline 360 & 110 & 10 & 1 \\
\hline
\end{tabular}

\section{RESULTS}

In this section, the ultimate and fatigue results from the simulation-length study are presented.

\subsection{Ultimate Loads}

Using the procedure detailed in Section 2.2 that selects the absolute maximum load across all simulations, the ultimate loads were calculated from the differing length simulations. Figure 5 shows a plot of the ratios of the ultimate loads of longer simulations compared to the 10-minute simulations, for four selected load channels. As in Figure 3, these loads represent the single highest load over all simulations of the length shown.

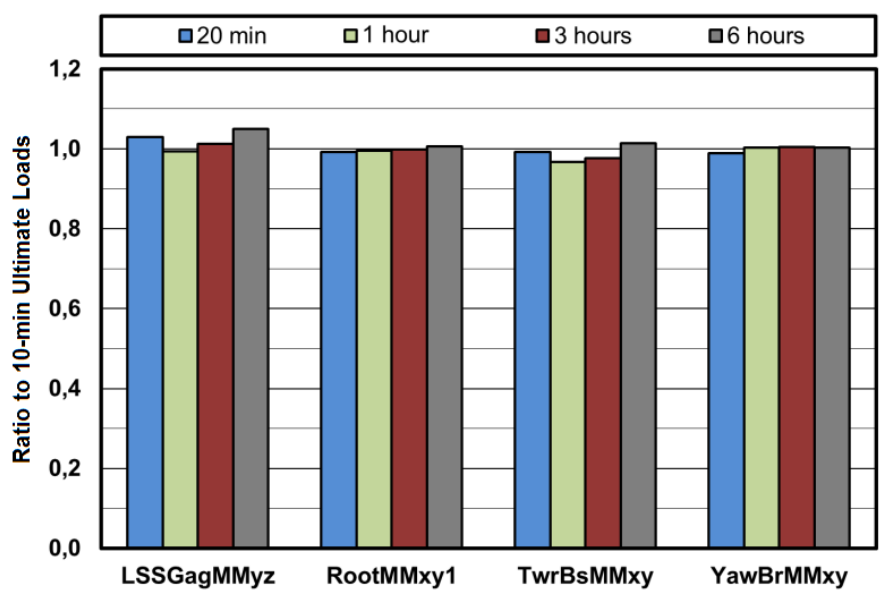

Figure 5. Ratios of 20-minute, 1-hour, 3-hour, and 6-hour ultimate loads to 10-minute ultimate loads. (LSSGagMMyz = bending moment on rotor shaft, RootMMxy1 = bending moment at the root of blade 1, TwrBsMMxy = tower-base bending moment, YawBrMMxy = yaw-bearing bending moment).

Like Figure 3, there is some noise in the ultimate loads, because this plot is based on single events from the total 60 hours of simulation. However, Figure 5 shows no trend in the ultimate loads with increasing simulation length.

\subsection{Convergence of Statistics}

The current offshore standard recommends 6 10minute simulations. There was concern that this was insufficient for proper convergence of the statistics 
of the loads, so an investigation was performed using the 10-minute simulation results. Specifically, we were interested in the convergence of loads caused by the wave inputs only. For this reason, we used groups of 10-minute simulations that shared the same wind inputs. For each wind bin, there were 10 groups of 36 simulations that have identical wind (see Table 2). A Monte Carlo selection process was used to select 1000 subgroups of varying size from 1 to 30 simulations out of these 36 simulations. Statistics of various parameters were calculated for each of these subgroups, which were then compared to the statistics of all 36 simulations - considered here to be the "true" values.

The convergence of the mean value of fore-aft tower-base bending moment can be seen in Figure 6 . In this figure, the individual points represent the average mean loads from the randomly selected subgroups of simulations. The solid line is the $95 \%$ confidence interval. With as few as two simulations, there is a $95 \%$ confidence of being within $\pm 0.1 \%$ of the true mean value. Figure 7 shows the convergence of the average of the maximum values from each simulation. The maximum values need more simulations to converge, requiring approximately 10 simulations to be within $\pm 2 \%$ of the true value.

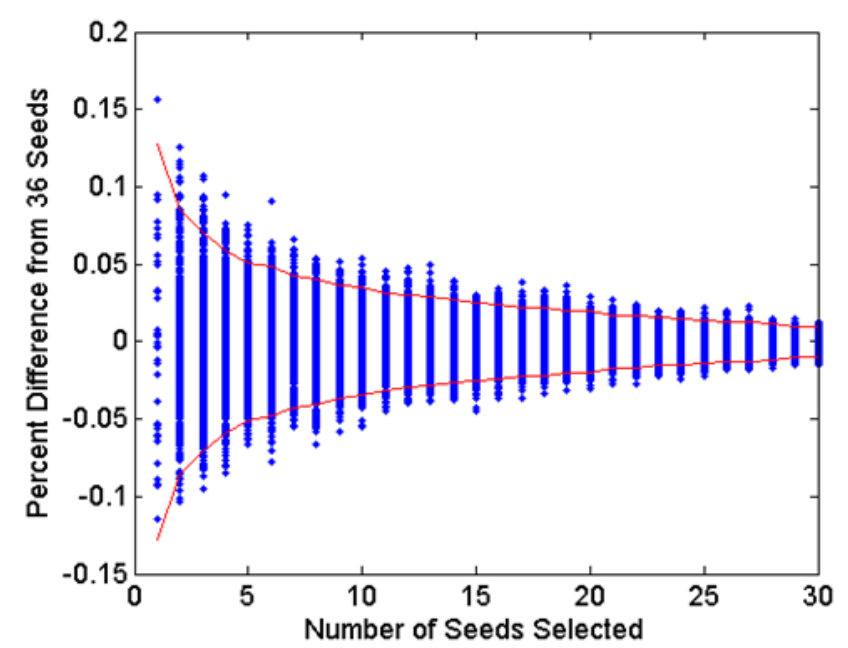

Figure 6. Convergence of mean value of fore-aft tower-base bending moment.

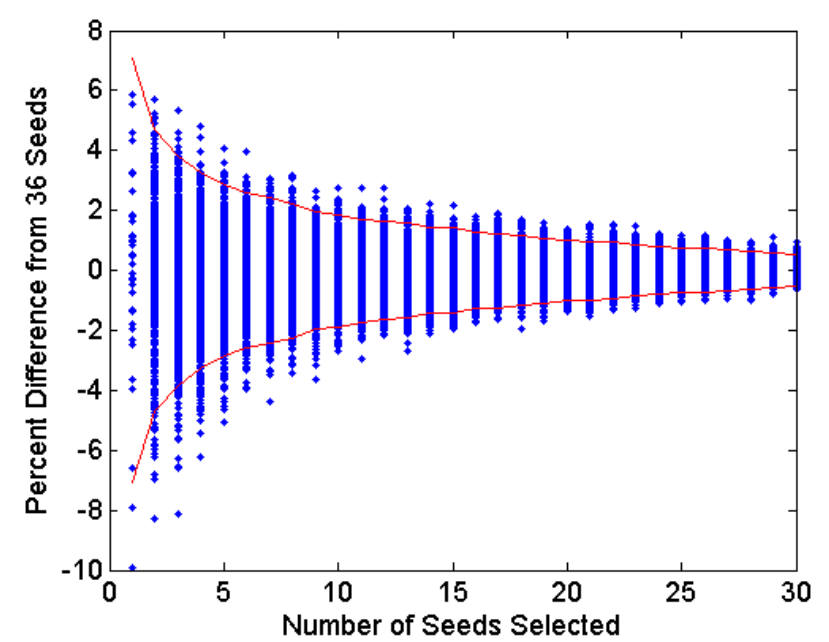

Figure 7. Convergence of maximum value of fore-aft towerbase bending moment.
The convergence of the average value of standard deviation can be seen in Figure 8. This plot was created by taking the average of the standard deviation of the tower-base bending load from each simulation in the subgroup, and comparing this to the average of the standard deviation of every simulation.

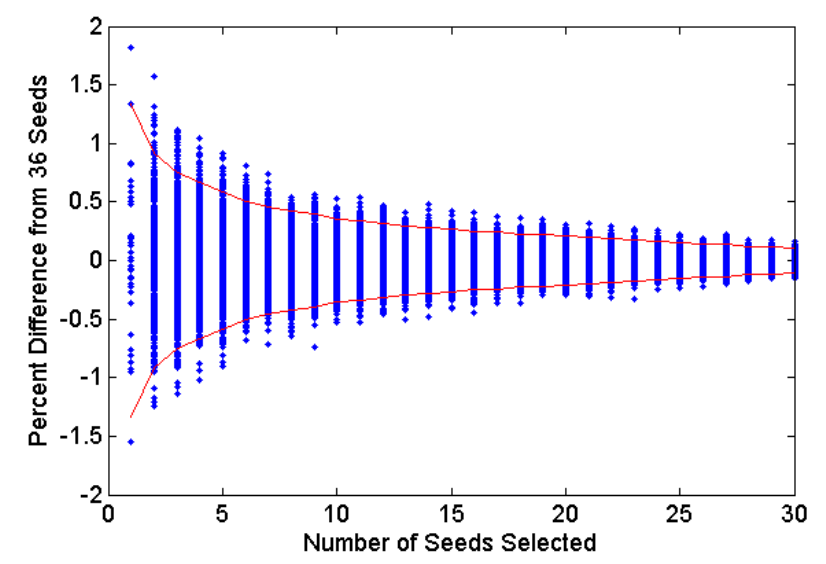

Figure 8. Convergence of standard deviation of fore-aft tower bending moment.

These results show reasonable convergence for the mean and standard deviation using the current recommendation of six random seeds. However, the maximum values may require more seeds to converge, depending on the accuracy required. In addition, the results presented in this section all used identical wind inputs; a similar analysis should be performed using both random wind and wave inputs to determine the final recommendation of the required number of seeds.

\subsection{Fatigue Analysis}

The processing of the fatigue data was conducted using MLife, which uses a rainflow-counting algorithm to count damage-equivalent loads (DELs) for each simulation, and applies a probability distribution and material properties to estimate lifetime damage and time to failure. Initial results, seen in Figure 9, showed that fatigue loads increased slightly as the simulation length increased. This result was contrary to the results from the ultimate load analysis (Sec. 3.1), so further investigation into the reasons behind this increase were conducted (Haid 2013b). 


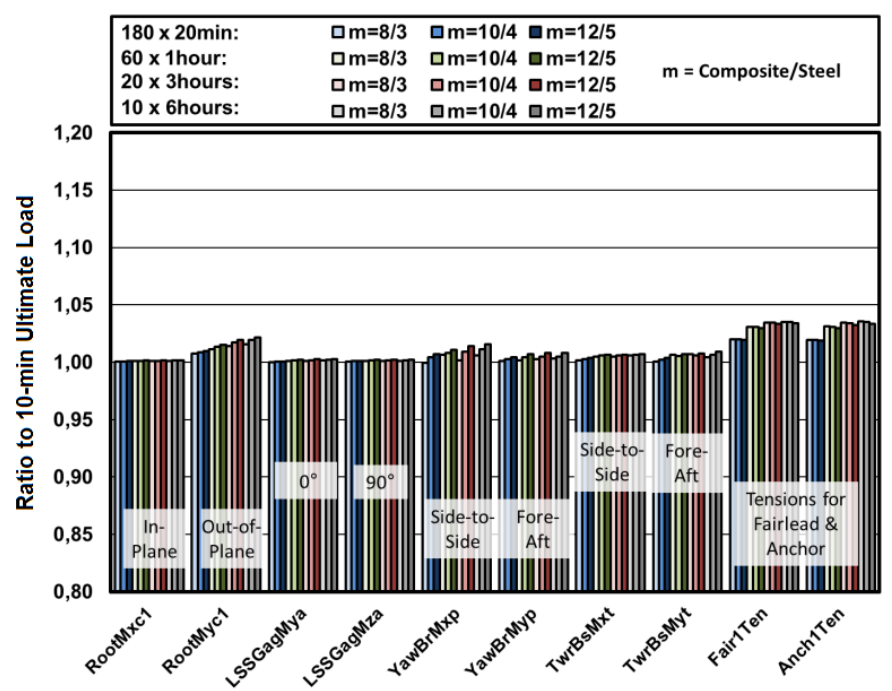

Figure 9. Ratios of various simulation-lengths DELs to 10minute simulation DELs. (X-axis from left to right: edgewise blade 1 root-bending moment, flapwise blade 1 root-bending moment, horizontal rotor shaft-bending moment, vertical rotor shaft-bending moment, side-side yaw-bearing bending moment, fore-aft yaw-bearing bending moment, side-side towerbase bending moment, fore-aft tower-base bending moment, fairlead tension, and anchor tension.)

The cause of the increase in fatigue loads with increasing simulation length was determined to be related to the way unclosed cycles were counted in the rainflow-counting algorithm. Unclosed cycles, also called half or partial cycles, are generated by rainflow-counting algorithms when peaks cannot be matched with equivalent but opposite amplitude valleys (Downing 1982). Unclosed cycles are created at the beginning and end of the time-series, and for large amplitude cycles. A weighting factor between zero and one is applied to these unclosed cycles when the final damage is calculated. In MLife, this weighting factor is known as UCMult. If a weighting factor of one is used, each unclosed cycle is treated as if it were a full cycle, and if zero is used, the unclosed cycles are disregarded, having no effect on the fatigue calculation. A factor of 0.5 is commonly recommended as a compromise. Figure 10 shows the effect of changing UCMult and simulation length on flap-wise blade-root bending fatigue.

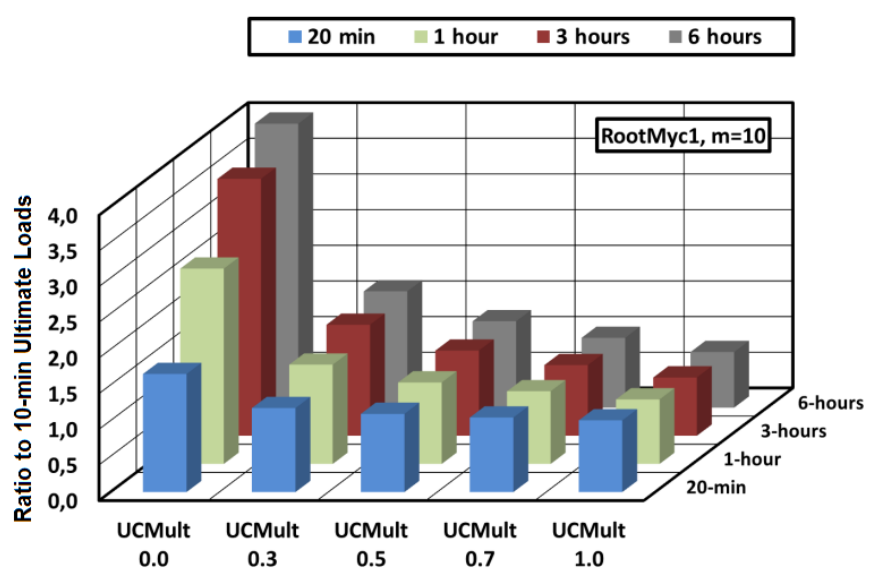

Figure 10. Flap-wise blade 1 root-bending fatigue as a function of UCMult and simulation length shown as a ratio to 10 -minute fatigue.

In Figure 10, the effect of different UCMult values can be clearly seen. For UCMult equal to one, fatigue loads are actually higher for shorter simulations. This is because there are more unclosed cycles compared to the total number of cycles for shorter simulations, so treating these as full cycles led to higher fatigue. For lower UCMult values, the longer simulations showed drastically higher fatigue loads when compared to shorter simulations. Once again, this was because of the ratio of unclosed cycles to closed cycles. Figures 11 and 12 show plots of the load ranges and resulting damage values for a UCMult value of 0.5 and 1.0, respectively. It can be seen that there is a large difference in the damage caused by load ranges between 8,000 and 16,000 $\mathrm{kNm}$ between the two figures.

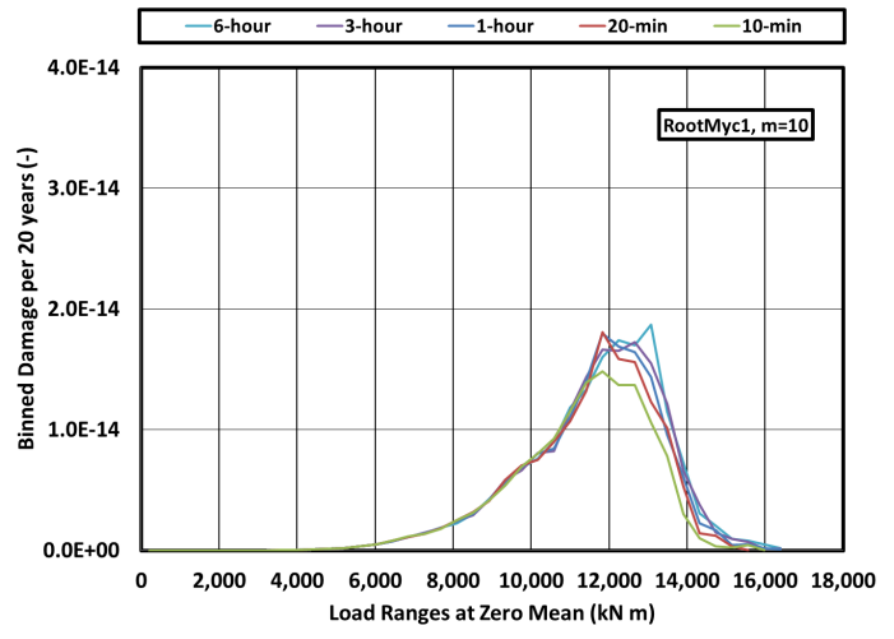

Figure 11. Fatigue damage versus load range for a UCMult value of 0.5 . 


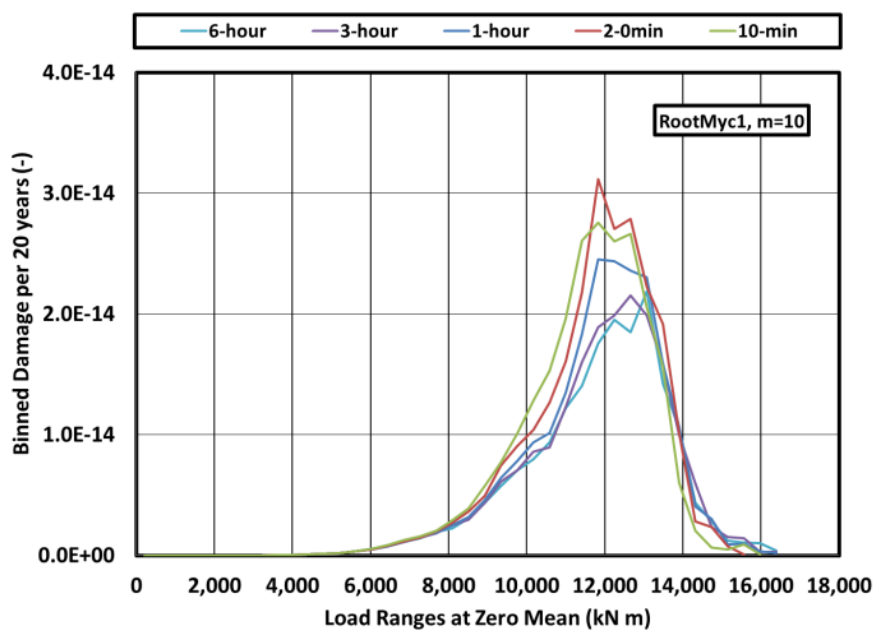

Figure 12. Fatigue damage versus load range for a UCMult value of 1 .

To prove that this effect was caused by the algorithm and not any physical phenomena, the group of 6-hour simulations was divided into 10-minute sections. A fatigue analysis was performed on these 10minute sections using UCMult equal to 0.5 , and it was found that the fatigue was once again lower than the 6-hour result. It was determined that one way to reconcile this problem would be to generate equivalent UCMult values that could be matched with each simulation length to produce the same results as the 6-hour simulations.

The equivalent UCMult values were created by dividing the 6-hour simulations into the various time lengths, and a parametric study was conducted to find the UCMult value that gave approximately the same fatigue as the 6-hour value with UCMult equal to 0.5 . Some issues were found with this approach. The equivalent UCMult value depends not only on simulation length, but also on the material exponent (m) used in the fatigue calculation, and the type of load. Figure 13 shows the dependence of the equivalent UCMult value on the material exponent.

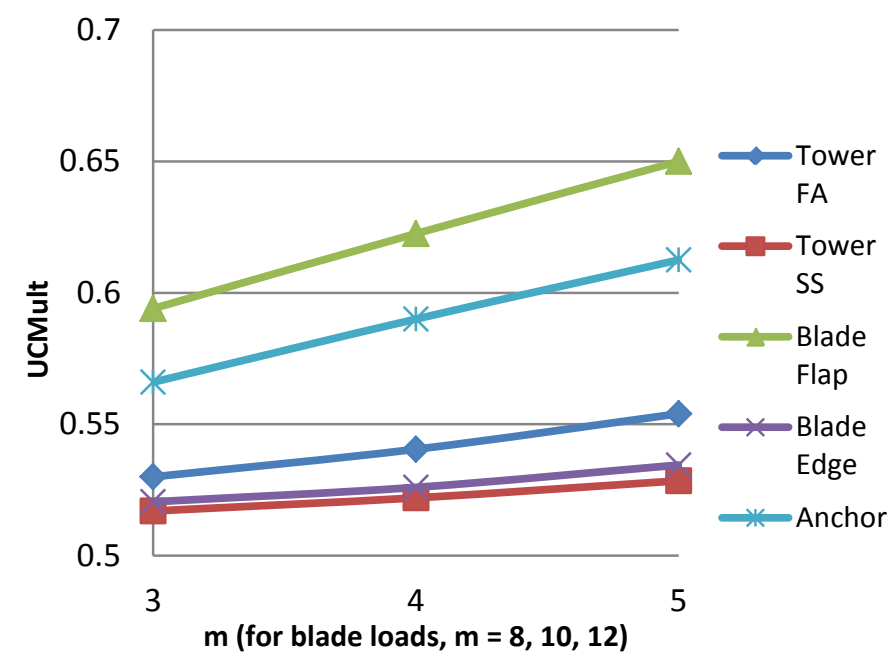

Figure 13. Equivalent UCMult values as a function of $\mathrm{m}$ for 10-minute simulations.
Figure 11 shows that there is a linear trend with $\mathrm{m}$, but the slope and intercept of the line depends on the load in question. This means that to get a fatigue result equivalent to the 6-hour result, a different UCMult value would have to be specified for each load in question and each value of $\mathrm{m}$. Figure 12 shows the equivalent UCMult values as a function of simulation length for a single $\mathrm{m}$ value.

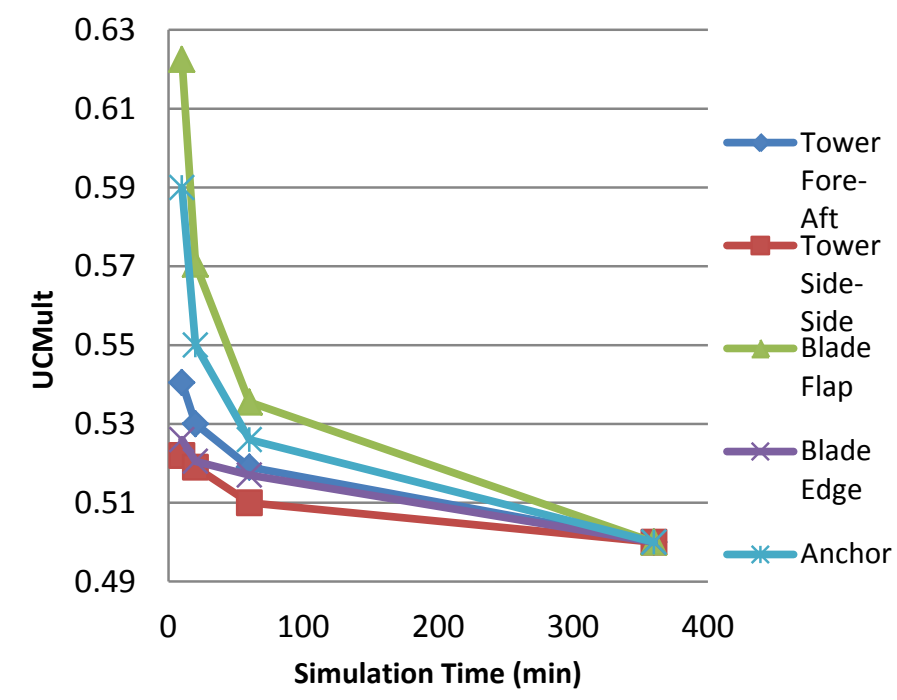

Figure 14. Equivalent UCMult values as a function of simulation length for $m=4 / 10$.

In Figure 14, the values asymptotically approach the 6-hour value of 0.5 . Functional fits could be made to predict the required equivalent UCMult value as a function of $\mathrm{m}$ and simulation length, but there is no clear way of creating a fit for the differences between output loads.

As an alternative to developing a complex functional fit that requires using different UCMult values for each output of interest, combinations of shorter simulations can be used to create a more accurate fatigue estimation. The current offshore design standard calls for 6 random seeds of 10-minute simulations. If these simulations are combined into one long time series before the fatigue calculation is performed, the extra length causes the algorithm to complete more of the unclosed cycles, and gives fatigue values that have the same accuracy as simulations with the same total time. Figure 15 shows the convergence of blade flapwise fatigue as a function of total time. 


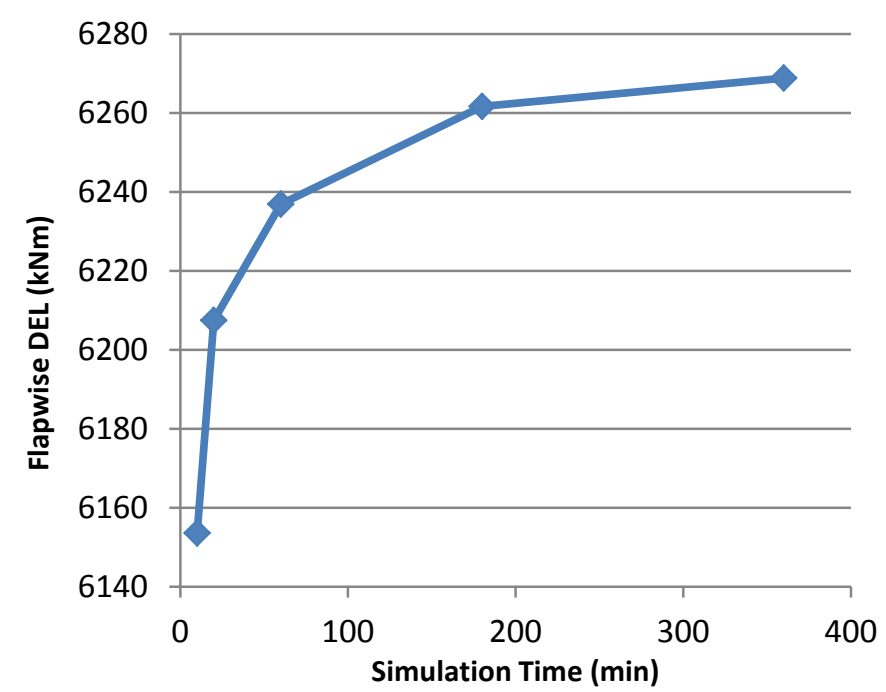

Figure 15. Blade 1 root flapwise damage equivalent load (DEL) as a function of simulation length for $m=4 / 10$.

By simply performing the fatigue analysis on the combined 1-hour time series rather than each of the six 10-minute simulations, the percent difference from the "true" DEL is reduced from $2 \%$ to $0.5 \%$.

\section{CONCLUSIONS}

Simulation length is an important consideration for design standards. With oil and gas floating platforms, slow natural periods of motion and secondorder hydrodynamic effects create the need for long simulations. For floating offshore wind turbines, no such need has been identified, at least for the spar buoy platform. Trends were found in both ultimate and fatigue calculations, but were determined to be a result of the algorithm used in both cases.

For ultimate loads, the averaging technique is very important. To compare ultimate loads from different length simulations, one should either compare the extreme load from the same total simulation length, or divide the longer simulations into the length of the shortest simulation and compare the average maxima.

With fatigue load calculations, the relatively greater number of unclosed cycles in shorter simulations plays an important role. It is possible to create an equivalent unclosed cycle weighting factor to solve this problem, but this method is complex. A simpler method to calculate fatigue involves performing the fatigue-counting algorithm on all of the simulations from each bin combined into one dataset instead of separately. This technique will be more important if low partial-cycle weighting factors are used, because these low weighting factors caused the most difference between fatigue values from different length simulations. Most importantly, there was no physical cause found in this study that necessitates longer simulations than the standard 10 minutes for the OC3-Hywind floating wind system.

\section{ACKNOWLEDGMENTS}

The University of Massachusetts authors are supported by the Offshore Wind Energy Engineering, Environmental Science, and Policy IGERT, number 1068864.

The NREL authors performed this work in support of the U.S. Department of Energy under contract number DE-AC36-08GO28308.

The help of Bonnie Jonkman, Marshall Buhl Jr., and Greg Hayman were essential for the success of this work.

\section{REFERENCES}

Downing, S. 1982. Simple Rainflow Counting Algorithms. International Journal of Fatigue 4(1): 31-40.

Haid, L. Loads Analysis of Offshore Floating Wind Turbines. M.S. Thesis. (to be published 2013). Haid, L. et al. 2013. Simulation Length Requirements in the Loads Analysis of Offshore Floating Wind Turbines. Proceedings of the ASME 2013 32nd International Conference on Ocean, Offshore and Arctic Engineering. June 9-14. Nantes, France.

Hayman, G.L. 2012. MLife Theory Manual for Version 1.00. NREL. [Online].

ble: http://wind.nrel.gov/designcodes/postproce ssors/MLife/.

IEC 61400-1 Ed.3. 2005. Wind Turbines-Part 1: Design Requirements. International Electrotechnical Commission.

IEC 61400-3 Ed.1. 2009. Wind Turbines-Part 3: Design Requirements for Offshore Wind Turbines. International Electrotechnical Commission.

Jonkman, B.J. 2009. TurbSim User's Guide: Version 1.50. NREL/EL-500-46198.

Jonkman, J. 2009. Dynamics of Offshore Floating Wind Turbines - Model Development and Verification. Wind Energy 12.

Jonkman, J. 2010. Definition of the Floating System for Phase IV of OC3. NREL/TP-500-47535.

Jonkman, J. \& Buhl, M. 2005. FAST User's Guide. NREL/EL-500-38230.

Jonkman, J. et al. 2009. Definition of a 5-MW Reference Wind Turbine for Offshore System Development. NREL/TP-500-38060.

Jonkman, J. \& Matha, D. 2011. Dynamics of offshore floating wind turbines - analysis of three concepts. Wind Energy 14: 557-569.

Roald, L., Jonkman, J., Robertson, A., \& Chokani, N. 2013. Effect of second-order hydrodynamics on floating offshore wind turbines. DeepWind'2013, 10th Deep Sea Offshore Wind R\&D Conference. 24-25 January 2013. Trondheim, Norway. 